\title{
Effect of Ultrasonic Surface Impact on the Fatigue Behavior of Ti-6Al-4V Subject to Simulated Body Fluid
}

\author{
Xiaojian Cao ${ }^{1,2}$, Xiaoli Xu ${ }^{1}$, Chong Wang ${ }^{2}$, Youngshik Pyoun ${ }^{3}$ and Qingyuan Wang ${ }^{2, *}$ \\ 1 School of Architecture Engineering, Nantong University, Nantong 226019, China; \\ johnson234@126.com (X.C.); xuxiaoli@ntu.edu.cn (X.X.) \\ 2 Department of Mechanics and Engineering Science, Sichuan University, Chengdu 610065, China; \\ wangchongscu@163.com \\ 3 Department of Mechanical Engineering, Sun Moon University, Asan 336708, Korea; pyoun@sunmoon.ac.kr \\ * Correspondence: wangqy@scu.edu.cn; Tel.: +86-139-8095-5902
}

Received: 26 September 2017; Accepted: 11 October 2017; Published: 18 October 2017

\begin{abstract}
The effect of ultrasonic nanocrystal surface modification (UNSM) on the fatigue behavior of Ti6Al4V (TC4) in simulated body fluid (SBF) was investigated. UNSM with the condition of a static load of $25 \mathrm{~N}$, vibration amplitude of $30 \mu \mathrm{m}$ and 36,000 strikes per unit produced about $35 \mu \mathrm{m}$ surface severe plastic deformation (SPD) layers on the TC4 specimens. One group was treated with a hybrid surface treatment (UNSM + TiN film). UNSM technique improves the micro hardness and the compressive residual stress. The surface roughness is increased slightly, but it can be remarkably improved by the TiN film. The fatigue strength of TC4 is improved by about $7.9 \%$ after UNSM. Though the current density of corrosion is increased and the pitting corrosion is accelerated, UNSM still improved the fatigue strength of TC4 after pre-soaking in SBF by $10.8 \%$. Interior cracks initiate at the deformed carbide and oxide inclusions due to the ultrasonic impacts of UNSM. Corrosion products are always observed at the edge of fracture surface to both interior cracks and surface cracks. Coating a TiN film on the UNSMed surface helps to improve the whole properties of TC4 further.
\end{abstract}

Keywords: nanocrystal surface modification; fatigue; crack; polarisation curve; simulated body fluid

\section{Introduction}

The surface condition is of particular importance to the fatigue properties of metals. Most failures are sensitive to the properties and micro-structures of the surface. If the surface conditions were optimized, the overall performance of materials shall be enhanced. Coarse grains can effectively restrain the propagation of cracks, while fine grains can effectively restrain the initiation of cracks [1,2]. The inducement of a nanostructured surface layer may therefore influence both the initiation and the growth of cracks. By means of coating and deposition technologies (Physical Vapor Deposition, chemical vapor deposition, electroplating and electrodeposition), it can be achieved. However, an accompanying tensile stress may easily initiate a microcrack between the coated layer and the substrate.

Surface self nanocrystallization (SSN) [3] induced by mechanical process has been developed in the recent two decades. The mechanical processes include surface mechanical attrition treatment (SMAT) [3,4], ultrasonic shot peening (USSP) [5], laser shock peening (LSP) [6], ultrasonic surface rolling processing (USRP) [7], ultrasonic cold forging technology (UCFT) [8], and so on. These techniques help to transform the coarse grains of a bulk material into nanosized grains by surface severe plastic deformation (SPD). They induce nanograins and grain size gradients into the surface region of bulk metals and alloys without changing the chemical compositions. Using transmission electron 
microscope (TEM), the grain refinement mechanisms induced by SPD for materials have been studied by many researchers [3-5,9-13]. The generation of dislocations, twinning, and development of grain boundaries with high angle misorientation are considered as the mainly reasons. The above techniques have been shown to improve the tensile strength [4], hardness [8,14], residual stress [4,8,14], wear resistance $[8,13,14]$, and especially fatigue properties [8,15-17] of materials.

Titanium alloys, in view of their high strength-to-weight ratio and excellent corrosion resistance, has been widely used in biomedical implants. Implants that function as bones, such as artificial joint endoprostheses, hip joints, bone plates, and tooth roots, are used under severe oscillating loading conditions and some of them are usually subjected to long-term cyclic loading [18]. It is reported that fatigue fracture is the most part of mechanical failure of titanium alloy implants [18-20]. Therefore, the long life fatigue properties of titanium alloys should be investigated to adjust the design.

In the human body, the implants endure the corrosion of body fluid besides the forces (such as bending, torsion, extrusion and shrinkage of muscle). The implant materials should have good corrosion resistance and fine histocompatibility. Although a certain depth of the oxide scale supports the good corrosion resistance, clinical experience suggests that rupture of the passive film and obvious corrosion occur in titanium alloy implants after a long time in vivo service. In addition, titanium alloys are considered to be sensitive to the stress corrosion [21]. Therefore, the corrosion fatigue properties of titanium alloys in body fluid should be studied. Recently, bioactive membranes such as $\mathrm{TiO}, \mathrm{TiN}, \mathrm{ZrO}{ }_{2}$, hydroxyapatite and diamond-like carbon films have been developed onto titanium alloys to improve the wear ability and the adhesion of cells [22-25]. It is necessary to enhance the associativity of the films and the base materials. Tong et al. [26] reported that the nitriding temperature could be decreased to $300{ }^{\circ} \mathrm{C}$ (which is more than $200{ }^{\circ} \mathrm{C}$ lower than conventional treatment) with a SPD by means of SMAT. Wu et al. $[27,28]$ studied the influence of hybrid surface treatment (UNSM before or after plasma nitriding) on the fatigue properties of S45C, the $1 \times 10^{8}$ cycles fatigue strength was improved in an interval of nitriding time-duration. The hybrid surface treatment (SSN techniques + coatings/films) is prospectively to enhance the mechanical properties and biocompatibilities furthermore.

Ti6Al4V (TC4) is one of the most widely used titanium alloys. Though the high cycle fatigue (HCF) and the very high cycle fatigue behaviors of TC4 were investigated in previous papers [29,30], the reason for crack initiation from the surface or from both the surface and the interior at a stress ratio $r=-1$ is not clear. Liu et al. studied the effects of stress ratio (from -1 to 0.5 ) on fatigue crack initiation and propagation [31], all the specimens at $r=-1$ failed from the surface. The fatigue behavior of TC4 in $0.9 \%$ physiological saline solution [32] showed that the slope of S-N curve decreases as the dipping time increases. Liu et al. [33] studied the HCF behavior of TC4 in simulated body fluid (SBF), the endurance limit at $1 \times 10^{8}$ cycles of TC4 decreases by $7 \%$. The fatigue properties of magnesium alloy [34,35], ZrCuFeAlAg bulk metallic glass [36], niobium alloy [37], stainless steel [38], TiN- and DLC-coated stainless steel [39] in simulated body fluid have been studied in the recent five years. Bai et al. [40], Huang et al. [41], and Li et al. [42,43] reported that nanocrystal surface layers by SSN are conducive to the corrosion resistance, because of the high density grain boundaries and the deeper passive film.

In the present work, a nanostructured surface layer was prepared by means of ultrasonic nanocrystal surface modification (UNSM) on TC4. The microhardness, surface roughness and residual stress were measured. The effect of UNSM on axial symmetric tension-compression fatigue properties of TC4 pre-soaked in SBF was also investigated. The corrosion behaviors of nanocrystal surface layer were observed. In addition, a hybrid surface treatment (UNSM + TiN film) was prepared as a comparision group.

\section{Experimental Procedures}

The material used was a titanium alloy TC4 shaft with the following chemical composition (in wt. \%): C-0.007-0.01, Fe-0.017-0.02, N-0.007-0.009, O-0.190-0.195, H-0.001, Al-6.408-6.411, $\mathrm{V}-4.403-4.406$, and balance Ti. The initial specimens are stress-relief annealed at $650{ }^{\circ} \mathrm{C}$ for $4 \mathrm{~h}$. 
The specimens were machined to the dimensions shown in Figure 1 and all the specimens were polished using sandpaper from grade 120 to grade 1500 . The mechanical properties of TC4 are: yield strength $=1179 \mathrm{MPa}$, tensile stress $=1230 \mathrm{MPa}$, elongation $=16 \%$, and reduction of area $=10 \%$.

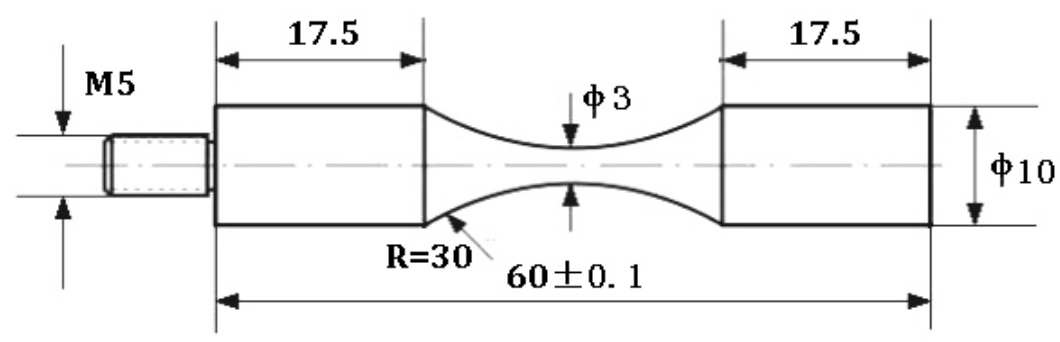

Figure 1. Dimension of the fatigue specimen (All dimensions are in $\mathrm{mm}$ ).

The principle of UNSM is introduced in reference [8]. An ultrasonic vibratory energy at a frequency of $20 \mathrm{kHz}$ is used, and tens of thousands of strikes per second are applied to the material surface as constant pressure [17]. These strikes cause SPD to the surface layer and induce a certain depth of nanocrystal structure. The static load applied on the specimens was $25 \mathrm{~N}$, and the vibration amplitude was $30 \mu \mathrm{m}$. The total load is the sum of the static load and the sinusoidal function of dynamic load. The number of vibration strike in this paper is 36,000 times $/ \mathrm{mm}^{2}$. Throughout the UNSM process, kerosene was used to avoid a temperature increase and protect the surface from oxidation.

An AIP system (Champion-Coating Co., Suzhou, China) was used to prepare TiN films onto the surface of TC4 after UNSM. The working pressure was $1 \mathrm{~Pa}$, the bias voltage cycle was $100 \mathrm{~V}$, the pulse bias was $300 \mathrm{~V}$ and the duty voltage was 30\%. An empirical time in which a thickness of approximate $5 \mu \mathrm{m}$ TiN film can be grown on TC4 was applied.

Cross-sectional observations of the samples were performed with an optical microscope (CMM-20E, Changfang, Chengdu, China) and a scanning electron microscopy (S-3400N, Hitachi, Nantong, China). The cross-sections were polished using SiC abrasive papers up to grade 1500, then on a polishing cloth with diamond suspensions. The specimens were finally etched at room temperature in Kroll's reagent $\left(\mathrm{HNO}_{3}: \mathrm{HF}: \mathrm{H}_{2} \mathrm{O}=3: 6: 90\right.$, vol \%).

The SBF was prepared according to the procedure proposed by Kokubo et al. [44]. The ion concentrations of SBF and human plasma are listed in Table 1. Three groups of specimens were dipped into SBF at $37^{\circ} \mathrm{C}$ for two weeks prior to the fatigue test. Thus, five groups of specimens, referred to as IS (stress-relief annealed initial specimens), UNSM (specimens subjected with UNSM), IS-SBF (specimens presoaked into SBF), UNSM-SBF (specimens presoaked into SBF after UNSM), and UNSM-TiN-SBF (specimens presoaked into SBF after coating a TiN film on UNSMed surface) were prepared. Corrosion resistance was evaluated by electrochemical techniques using a three electrode cell at $37 \pm 0.5^{\circ} \mathrm{C}$. Pt, saturated calomel electrode (SCE) and TC4 specimen were used as anode, reference electrode and working electrode respectively. SBF was the electrolyte. The cylindrical surface of arc segment was the working face. The anodic sweep was $30 \mathrm{mV}$ per minute.

Table 1. The ion concentrations of SBF and human plasma (mmol/L).

\begin{tabular}{clllccccc}
\hline Ions & $\mathbf{N a}^{+}$ & $\mathbf{K}^{+}$ & $\mathbf{C a}^{2+}$ & $\mathbf{M g}^{2+}$ & $\mathbf{H C O}^{3-}$ & $\mathbf{C l}^{-}$ & $\mathbf{H P O}_{4}{ }^{3-}$ & $\mathbf{S O}_{4}{ }^{2-}$ \\
\hline Human plasma & 142.0 & 5.0 & 2.5 & 1.5 & 27.0 & 103.0 & 1.0 & 0.5 \\
Simulated body fluid (SBF) & 142.0 & 5.0 & 2.5 & 1.5 & 4.2 & 148.5 & 1.0 & 0.5 \\
\hline
\end{tabular}

The microhardness of the nanostructured surface layer was measured using a Vickers hardness tester (MMT-7, Matsuzawa, Tokushima, Japan) with a load of $50 \mathrm{~g}$ and a time-duration of 20 s. The surface roughness was observed by a contact surface profiler (DEKTAK3, ULVAC, 
Tokushima, Japan). Asylum Research MFP-3D Atomic force microscope (AFM, FSM-Precision, Chongqing, China) was used to scan the surface topography after UNSM. The residual stress using was measured by X-ray diffraction (XRD, Rigaku X'pert pro MPD, Chengdu, China). The Cu K $\alpha$ radiation $(\lambda=1.54184 \AA$ ) was used, and the diffraction lattice plane (213) was examined within a range $2 \theta$ of $136-146^{\circ}$. Samples were electrolytic polished layer by layer from the surface to a depth of about $300 \mu \mathrm{m}$.

To investigate the effect of the nanostructured surface layer on the fatigue behavior of TC4, axial symmetric tension-compression fatigue tests (stress ratio $r=-1$ ) on the five groups of samples (IS, UNSM, IS-SBF, UNSM-SBF, UNSM-TiN-SBF) were conducted by a piezoelectric ultrasonic fatigue test machine (USF-2000, Shimadzu, Chengdu, China) at ambient temperature. The frequency of fatigue testing was $20 \mathrm{kHz}$. The specimen that was designed above can resonate longitudinally at the same frequency. The fracture surfaces and the corroded surface were observed using scanning electron microscopy (JSM-5900LV, 6510LV, and 7500F, JEOL, Chengdu, China). Energy-dispersive X-ray spectroscopy (EDX) was used to detect the composition of any inclusions which induced the inner crack initiation with JEOL JSM-7500F.

\section{Results and Discussion}

\subsection{Observation of the Severe Plastic Deformation Layer}

The microstructures of the SPD layers and the variation of grain size by depth as seen by the TEM and optical microscopes have been reported widely [1-13]. It is well concluded that nanocrystals can be obtained in these SPD layers. The mechanical properties of TC4 mainly depend on the component, size and shape of $\alpha$-phase. The microstructure and dissimilation surface layer of TC4 after UNSM are shown in Figure 2. The microstructure of IS is equiaxed structure. It can be concluded that a SPD layers with the thickness of $35 \mu \mathrm{m}$ was achieved. Hexagonal close packed (hcp) $\alpha$-phase has a high SFE more than $300 \mathrm{~mJ} / \mathrm{m}^{2}$ and body centered cubic (bcc) $\beta$-phase theoretically has 12 slip directions. The mechanism of grain refining in TC4 is mainly dislocation motion. Twinning is also found in $\alpha$-titanium because of the low symmetry of hexagonal [9].
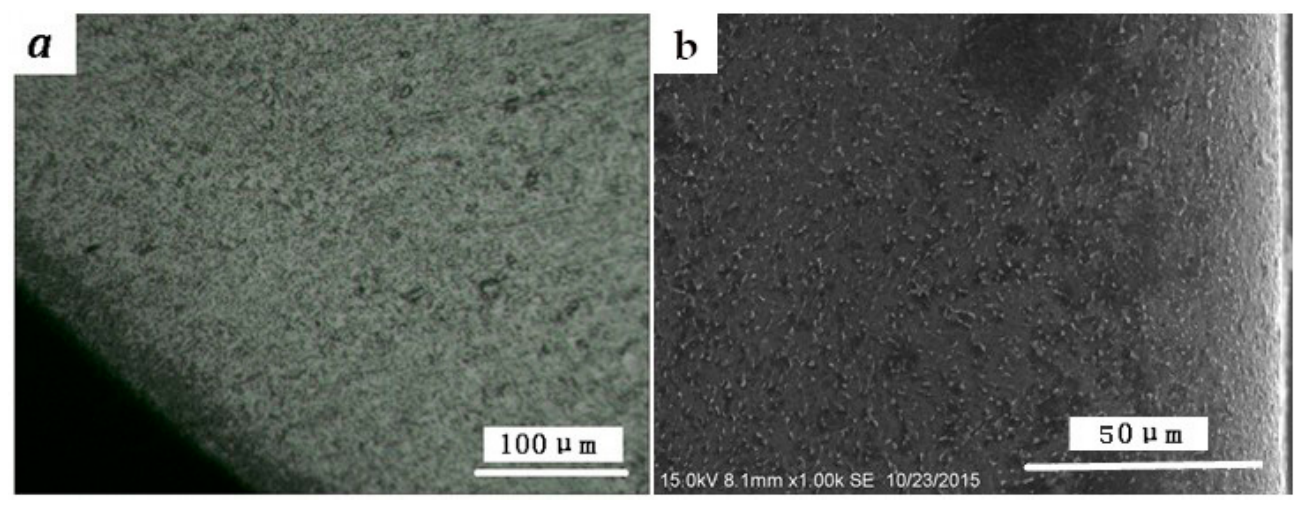

Figure 2. Microstructure and dissimilation surface layer of TC4 after ultrasonic nanocrystal surface modification (UNSM): (a) Optical micrograph; (b) scanning electron microscopy (SEM) micrograph.

\subsection{Micro Vickers Hardness and Residual Stress Distrubution}

The micro Vickers hardness along the depth from the surface to $400 \mu \mathrm{m}$ was measured, as depicted in Figure 3. The microhardness of the initial TC4 specimen (IS) was about $310 \mathrm{HV}$. The hardness of the surface after UNSM was increased by $22.6 \%$ compared with that of IS. The microhardness after UNSM rapidly decreases to about $200 \mu \mathrm{m}$, while it decreases gradually from the depth of $200 \mu \mathrm{m}$ to the core. The Hall-Petch theory illustrates that the hardness and the yield stress relate to the grain size, smaller grain has a higher hardness to the most materials. 


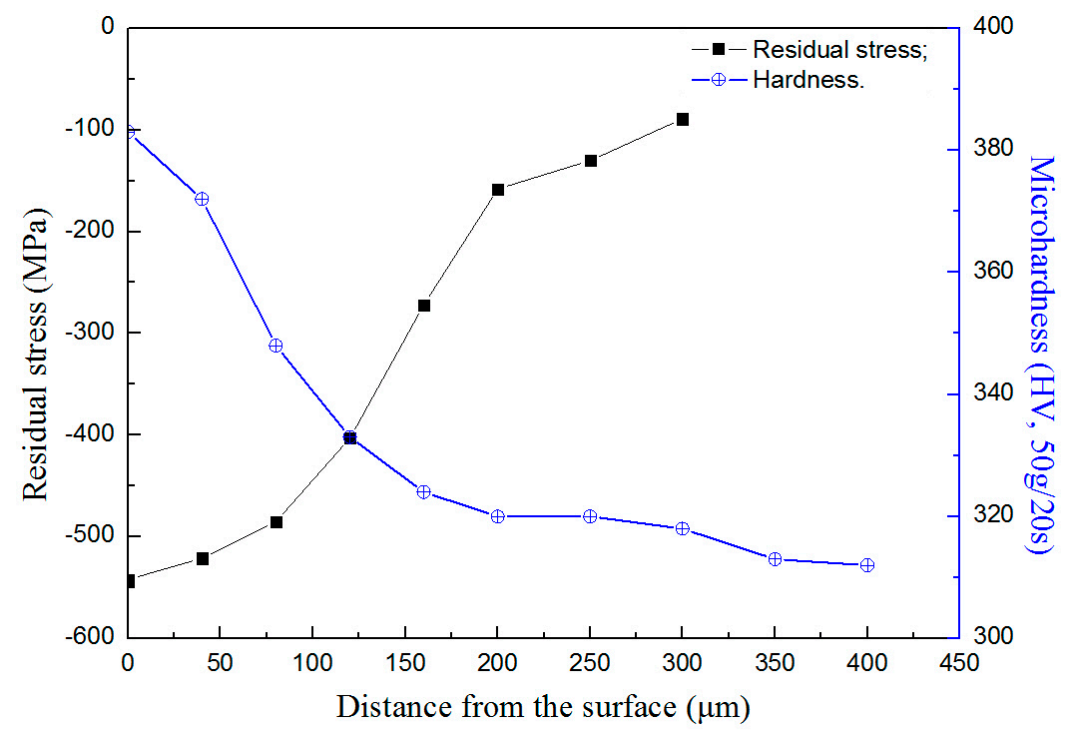

Figure 3. Distribution of compressive residual stress and micro Vickers hardness after UNSM.

High compressive residual stress can be induced in the SPD layer $[7,8,30]$. The surface residual stress of IS was $-19 \mathrm{MPa}$ with stress-relief annealing treatment. In this paper, the residual stress of UNSMed TC4 from the surface to the depth of $300 \mu \mathrm{m}$ was measured, as shown in Figure 3. It is obvious that the surface compressive residual stress was achieved. Compressive residual stress is the most crucial factor for increasing the fatigue resistance. The value of the surface compressive residual stress with UNSM was $544 \mathrm{MPa}$. The compressive residual stress gradually decreases to the depth of $80 \mu \mathrm{m}$, and then it rapidly decreases to the matrix. Noticeably, there is an intersection at the depth of $120 \mu \mathrm{m}$. The cores of interior cracks usually appear at the zone nearby the intersection, and which shall be discussed later.

\subsection{Surface Roughness and Surface Features}

Table 2 shows the surface roughness due to UNSM. The average roughness $R a$ of IS was $0.35 \mu \mathrm{m}$, and the $R a$ of UNSM was $0.50 \mu \mathrm{m}$. Though UNSM process increased the surface roughness of polished TC4 specimen, it is negligible comparing with the turned specimen which has a $R a$ of $2.16 \mu \mathrm{m}$. A better surface with a roughness down to $0.04 \mu \mathrm{m}$ was achieved to the hybrid surface treatment (UNSM + TiN film). UNSM helps to maintain a good surface roughness in this test.

Table 2. Surface roughness of TC4 after ultrasonic nanocrystal surface modification (UNSM).

\begin{tabular}{ccccc}
\hline Group & Initial TC4 Specimen after Polishing (IS) & UNSM & UNSM-TiN & Turned Specimen \\
\hline Average roughness & $0.35 \mu \mathrm{m}$ & $0.50 \mu \mathrm{m}$ & $0.04 \mu \mathrm{m}$ & $2.16 \mu \mathrm{m}$ \\
\hline
\end{tabular}

The surface features of TC4 are shown in Figure 4. After UNSM, many parallel lines caused by the process (the main feed of main shaft of the ultrasonic vibratory device) are seen to be spaced at about $80 \mu \mathrm{m}$. From the 3-D microscope image by AFM, it can be concluded that the deformations of TC4 grains on the surface have regular shape which mainly have an angle of about $30^{\circ}$ to the trace of UNSM process. With the micro concave-convex texture, it can be deduced that the surface area is increased. This might be beneficial for film coatings and cell adhesions. 

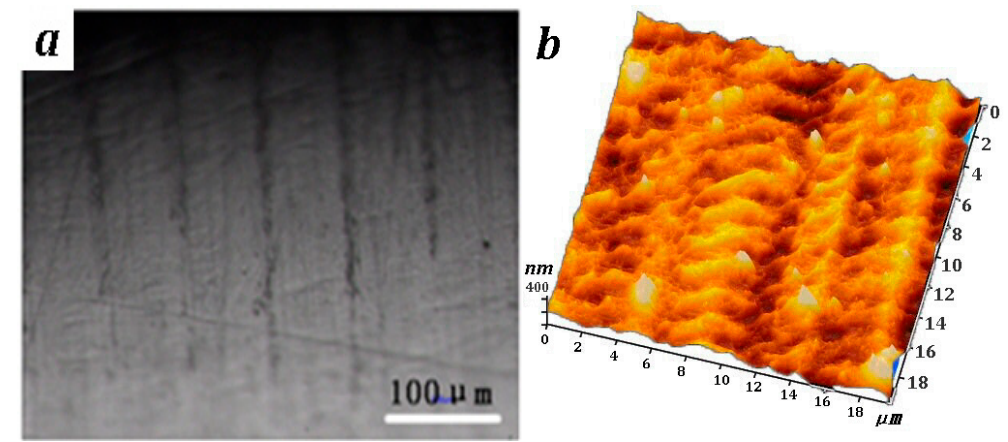

Figure 4. Surface feature of UNSM: (a) Optical micrograph; (b) 3-D microscope image by atomic force microscope (AFM).

\subsection{Corrosion Resistance}

The variations of nitrogen and oxygen of the hybrid surface treated specimen were measured along a diameter. Figure 5 gives the illustration of measurement and the results. The peaks of nitrogen and oxygen nearby surface are marked with a down arrow. The maximum value of nitrogen is at a depth of about $8 \mu \mathrm{m}$ (about $3 \mu \mathrm{m}$ deeper than that of experience). Underneath the TiN film, an ultrathin passive film of oxide exists. The content of nitrogen is more than oxygen till the depth of $150 \mu \mathrm{m}$, which is opposite to the chemical composition of the matrix mentioned above. Therefore, it can be concluded that the refined grains assist both the growth of TiN film and the diffusion of nitrogen.

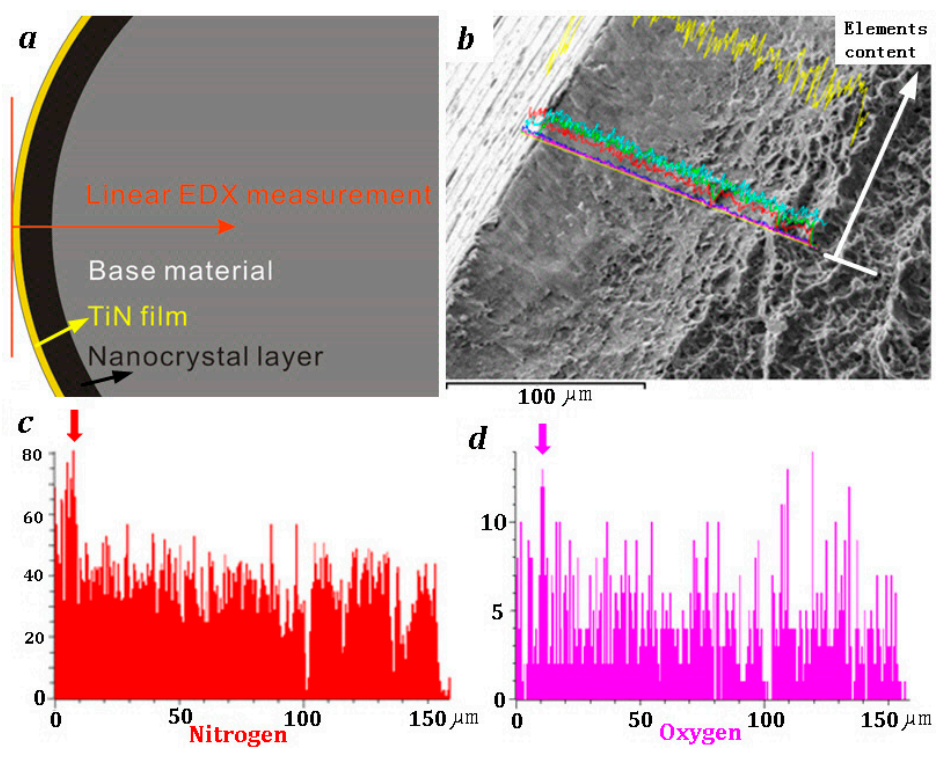

Figure 5. Analysis of TiN film on UNSMed specimen: (a) Illustration of measurement; (b) Measurement results (yellow curve is Titanium); (c) Variation of nitrogen; (d) Variation of oxygen.

Figure 6 shows the polarization curves of TC4 in SBF solution for $30 \mathrm{~min}$, and the observation of the surfaces subjected to SBF for 2 weeks is given in Figure 7. The curves of IS and UNSM are typical for passive materials with low current densities over a wide range of potentials. The passivation current density for UNSMed specimen is about $2.15 \times 10^{-6} \mathrm{~A} \cdot \mathrm{cm}^{-2}$, and it is the same with IS. However, there is no obvious passive region for UNSM-TiN because of the TiN film. The pitting corrosion potential $\left(E_{b}\right)$ of UNSM $(564 \mathrm{mV})$ is a little less than that of IS $(572 \mathrm{mV})$, and the electric potential of corrosion $\left(E_{\text {corr }}\right)$ shows the same result. However, the current density of corrosion $\left(I_{\text {corr }}\right)$ of UNSM calculated by Tafel extrapolation is $2.305 \mu \mathrm{A}$, which is much higher than that of IS $(1.001 \mu \mathrm{A})$. 
The nanocrystal surface layer accelerates the corrosion speed because of the high surface activity. Therefore, more eroding pits are observed on the surface of UNSM after pre-soaking in SBF for 2 weeks. The hybrid surface treatment has the best corrosion resistance with $E_{\text {corr }}$ of $-301 \mathrm{mV}$ and $I_{\text {corr }}$ of $0.655 \mu \mathrm{A}$, and nearly no eroding pit exists. The white particles on the dipped surface are various crystals due to SBF. The deposition of crystals is increased on UNSMed specimens.

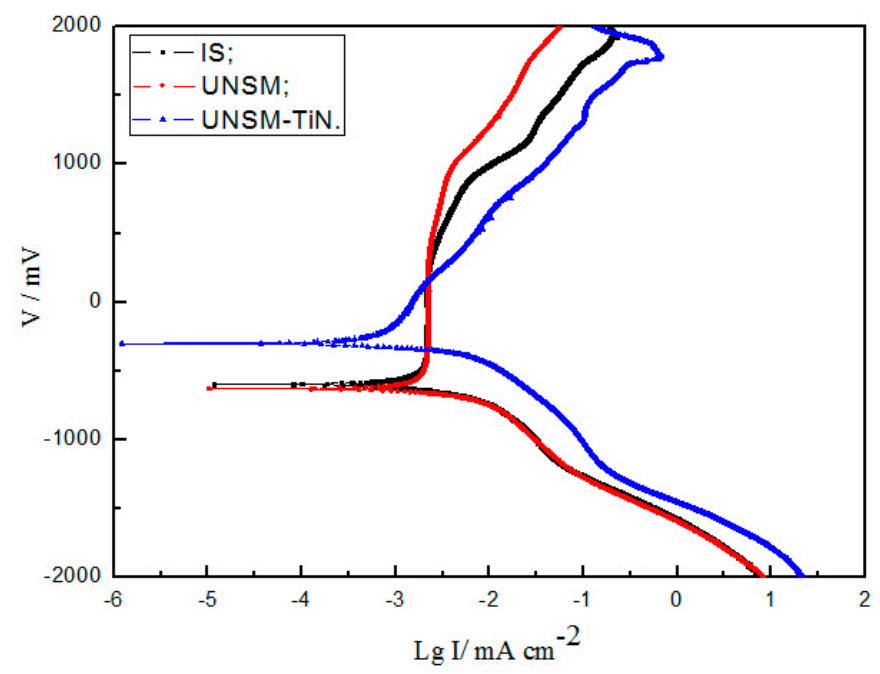

Figure 6. Polarisation curves in simulated body fluid (SBF) solution.

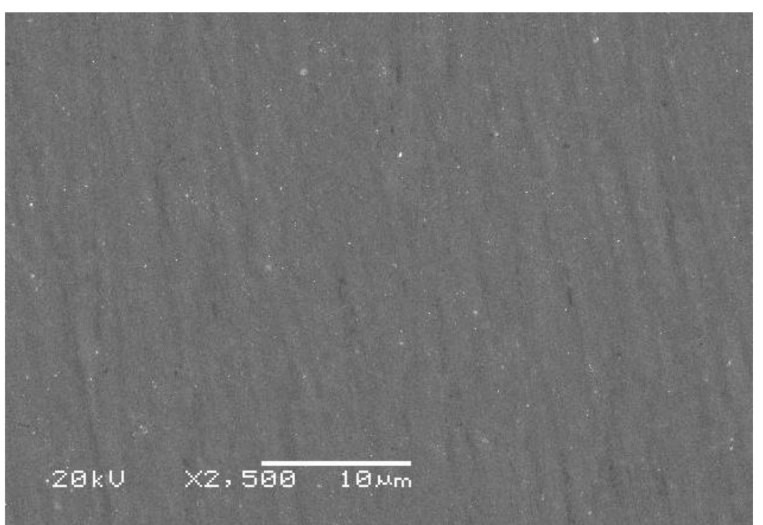

(a)

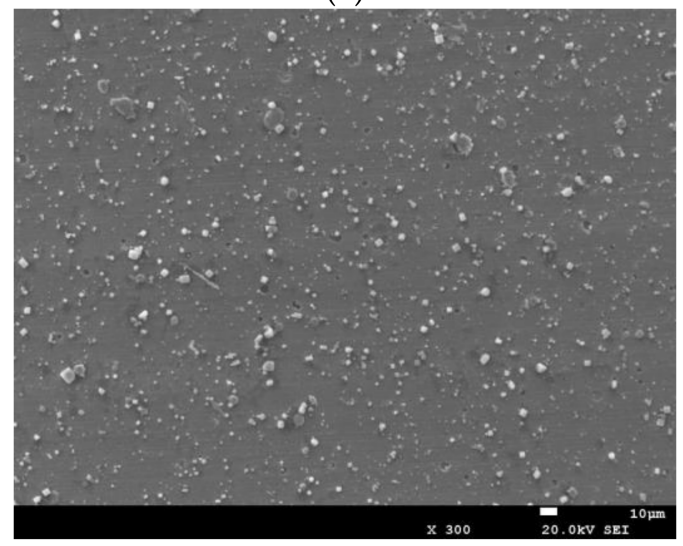

(c)

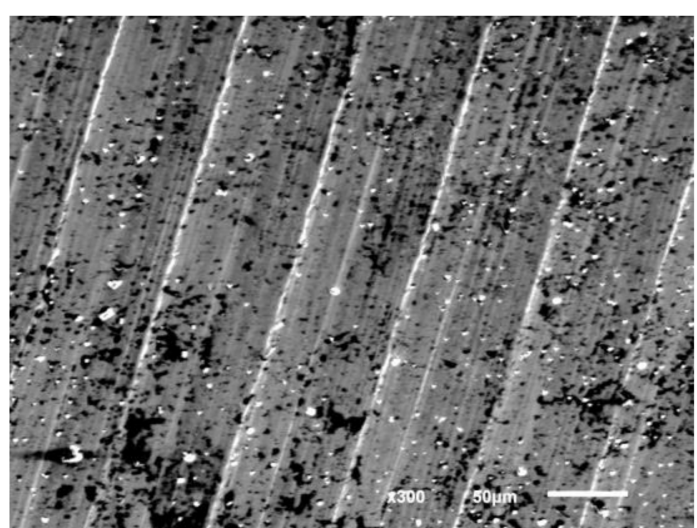

(b)

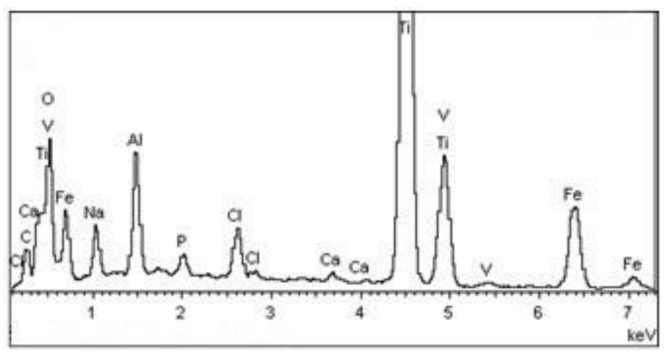

(d)

Figure 7. Observation of the surface subjected to SBF for 2 weeks: (a) IS; (b) UNSM; (c) UNSM-TiN (d) energy-dispersive X-ray spectroscopy (EDX) analysis of white crystals. 


\subsection{Fatigue Properties}

The fatigue characteristics of TC4 are shown in Figure 8. Specimens that did not encounter failure are shown as run-outs. Interior initiated cracks are marked with vertical bars. After UNSM, most cracks transform to be inner cracks while the fatigue lives are more than $1 \times 10^{6}$ cycles. On the contrast, cracks initiate at the surface to nearly all the un-UNSMed specimens, it is in accordance with which reported in Ref. [31]. Comparing with IS, the $1 \times 10^{8}$ cycles fatigue strength of UNSM is increased by $7.9 \%$. After 2 weeks in SBF, the fatigue strength of IS-SBF, UNSM-SBF, and UNSM-TiN-SBF were 530, 587 , and $630 \mathrm{MPa}$, respectively. The fatigue strength of UNSM-SBF is increased by $10.8 \%$ to IS-SBF. From the S-N curves, it is evident that UNSM improves the fatigue strength of TC4 in SBF. The fatigue strength of UNSM-TiN-SBF is even more than which of UNSM. Therefore, the hybrid surface treatment has a good prospect in clinical applications.

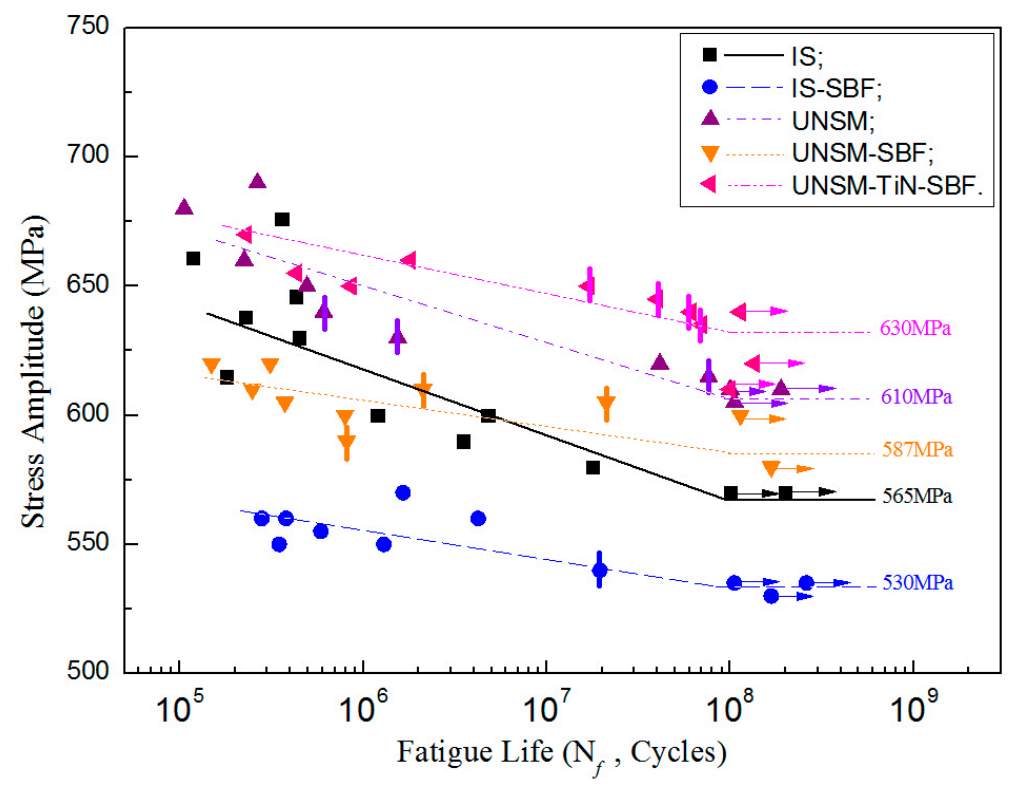

Figure 8. S-N curves of TC4 pre-soaked in SBF for 2 weeks.

To both IS and UNSM, the surface cracks usually initiate from surface defects at high fatigue stress. The only interior crack of IS-SBF is shown in Figure 9. The inclusion in crack core is carbide. There is an elliptic flat area which is considered to be the crack initiation zone, where the propagation lines of micro crack look like a dandelion. At the surface nearby the crack initiation, corrosion products due to SBF are observed. To SSN specimen, three lays are divided above the matrix. They are nano-structured layer, refined structured layer and deformed coarse grain layer [3]. The refined structured layer has a depth up to about $100 \mu \mathrm{m}$. After UNSM, deformed inclusions (high light white areas) are found at the zone with a depth of about 100-250 $\mu \mathrm{m}$ where the compressed residual stress decreases quickly, the hardness is closed to the core, plasticity and tenacity are weakened (Figures 10 and 11). This zone is deduced to be at the deformed coarse layer. The shapes of inclusions are long and narrow because of the ultrasonic impacts on the surface, and are nearly parallel to the edge of specimens. EDX shows that these inclusions are carbides and oxides. Even eroding pits on the surface are investigated above, the UNSM process still plays an active role in improving the fatigue properties. Corrosion products are also observed at surface crack initiations of UNSM-TiN-SBF specimens (Figure 12). Surface cracks initiate due to the surface defects (damage or defect of TiN film), similarly. The combination of plastic deformation and corrosion in SBF affects the crack initiations together. 


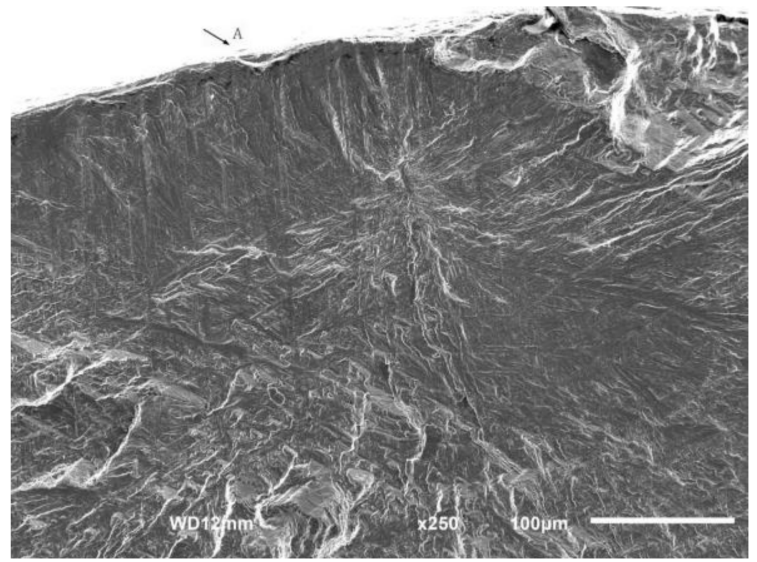

(a)

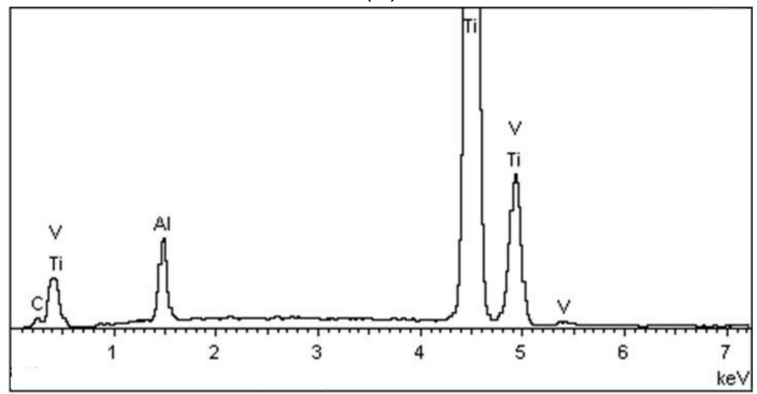

(b)

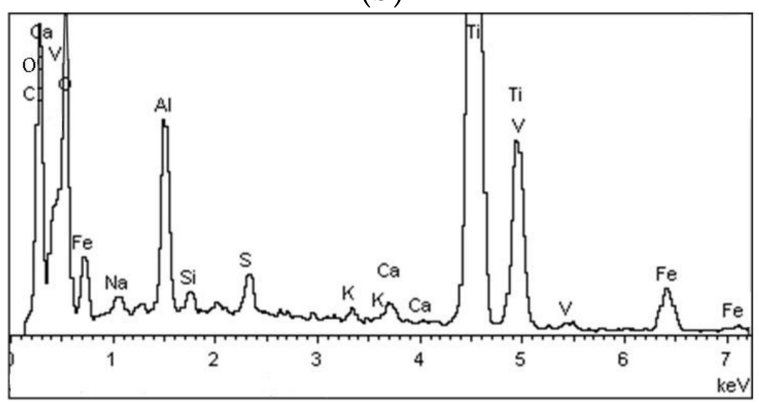

(c)

Figure 9. Fracture surface of TC4 (IS-SBF, $540 \mathrm{MPa}, 1.95 \times 10^{7}$ cycles): (a) crack initiation; (b) EDX analysis of crack initiation; (c) EDX analysis of point A.

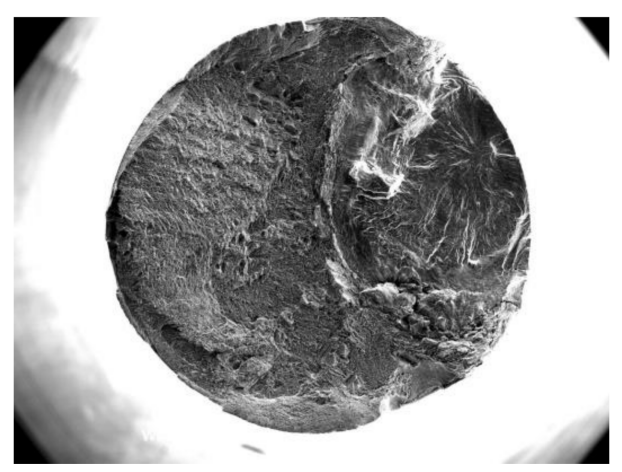

(a)

Figure 10. Cont. 


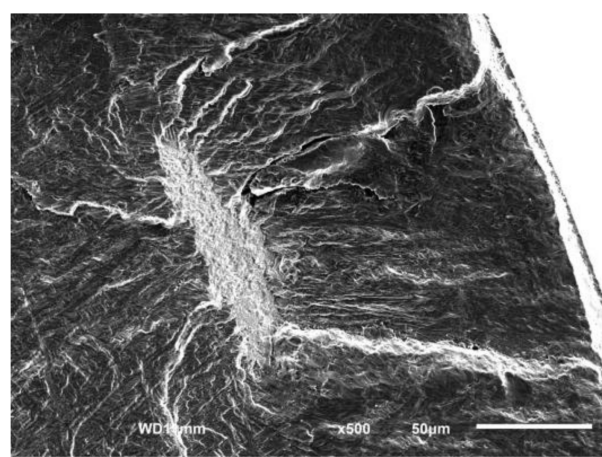

(b)

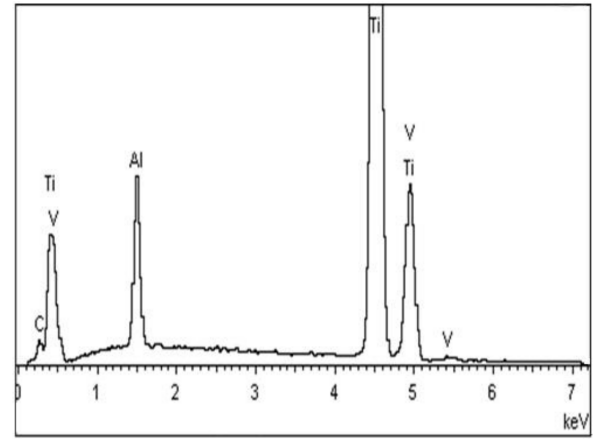

(c)

Figure 10. Fracture surface of TC4 (UNSM, $620 \mathrm{MPa}, 4.13 \times 10^{7}$ cycles): (a) Overall view of fracture surface; (b) Crack initiation; (c) EDX analysis of crack core.

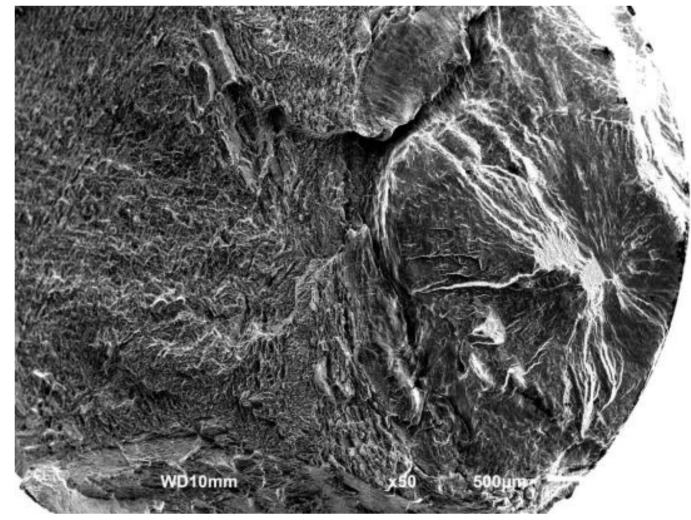

(a)

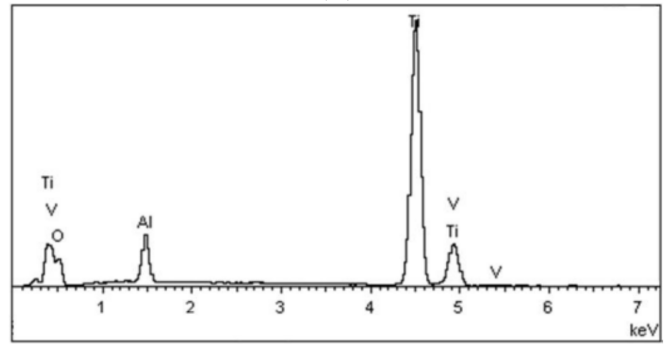

(c)

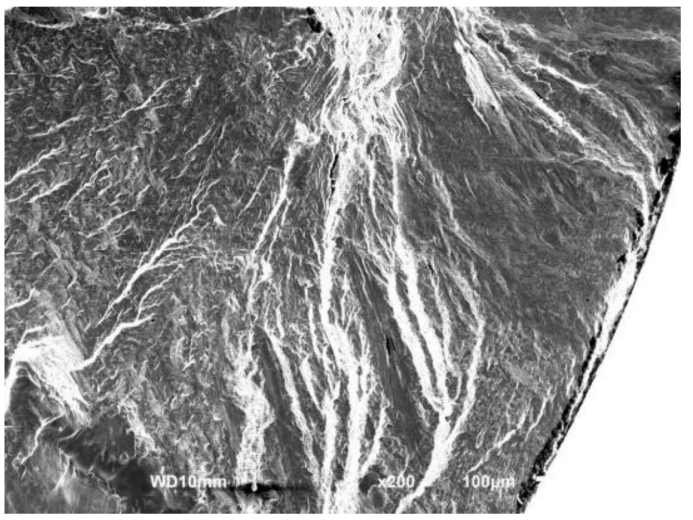

(b)

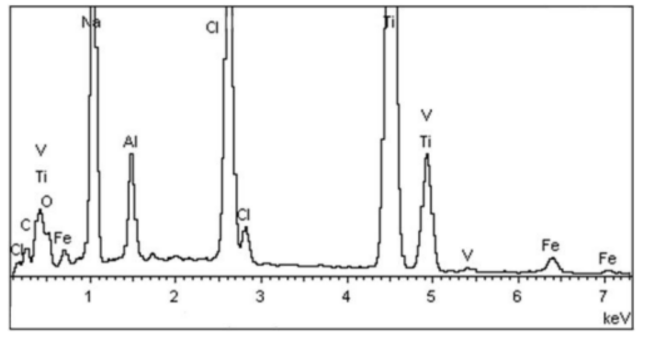

(d)

Figure 11. Fracture surface of TC4 (UNSM-SBF, $610 \mathrm{MPa}, 2.12 \times 10^{6}$ cycles): (a) Overall view of fracture surface; (b) Edge nearby the crack initiation; (c) EDX analysis of crack core; (d) EDX analysis of the edge. 


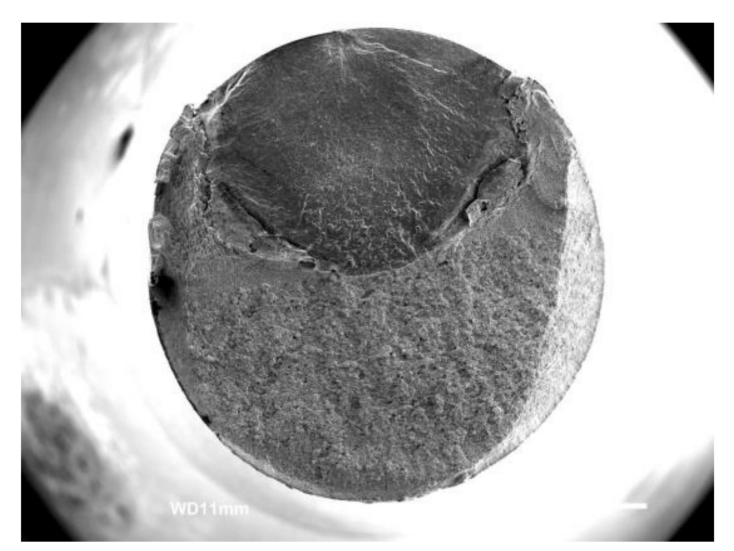

(a)

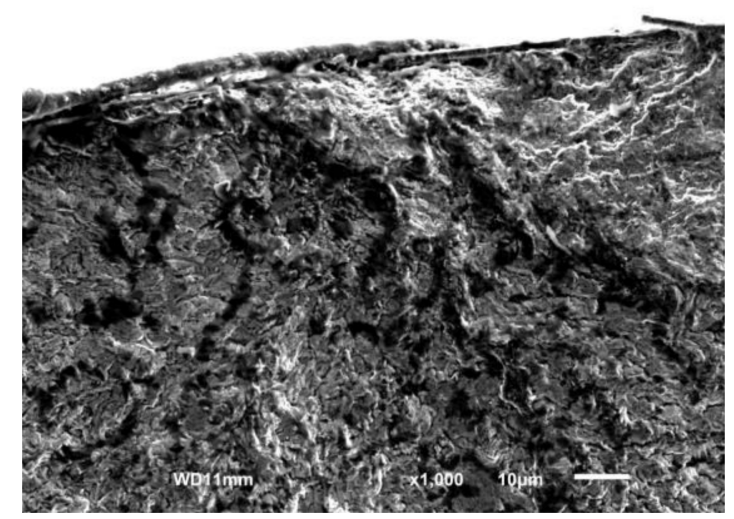

(b)

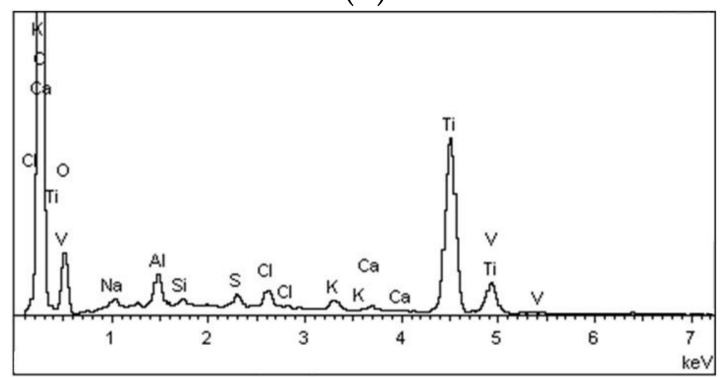

(c)

Figure 12. Fracture surface of TC4 (UNSM-TiN-SBF, $660 \mathrm{MPa}, 1.81 \times 10^{6}$ cycles): (a) Overall view of fracture surface; (b) Crack initiation; (c) EDX analysis of crack initiation.

\section{Conclusions}

1. UNSM technique improves the micro hardness and the surface compressive residual stress of TC4. UNSM helps to maintain a good surface roughness. The fatigue strength of TC4 is improved by about $7.9 \%$ after UNSM.

2. The current density of corrosion is increased after UNSM, and eroding pits obviously distribute on the surface of UNSMed TC4 specimen after two weeks in SBF. However, the fatigue strength of TC4 in SBF is improved by $10.8 \%$ after UNSM.

3. Interior cracks initiate at the deformed carbide and oxide inclusions due to the ultrasonic impacts of UNSM. Corrosion products are always observed at the edge of fracture surface to both interior cracks and surface cracks.

4. The hybrid surface treatment improves the whole properties of TC4 further. 
Acknowledgments: The financial support extended by National Natural Science Foundation of China (11327801 \& 11502152) and Natural Science Foundation of Jiangsu Province (BK20160416) are gratefully acknowledged.

Author Contributions: Q.W. conceived and designed the experiments; X.C. performed the experiments; X.X. analyzed the corrosion data; C.W. analyzed the micro pictures; Y.P. contributed the UNSM treatment; X.C. wrote the paper.

Conflicts of Interest: The authors declare no conflict of interest. The founding sponsors had no role in the design of the study; in the collection, analyses, or interpretation of data; in the writing of the manuscript, and in the decision to publish the results.

\section{References}

1. Wagner, L. Mechanical surface treatments on titanium, aluminum and magnesium alloys. Mater. Sci. Eng. A 1999, 263, 210-216. [CrossRef]

2. Vinogradov, A. Fatigue limit and crack growth in ultra-fine grain metals produced by severe plastic deformation. J. Mater. Sci. 2007, 42, 1797-1808. [CrossRef]

3. Lu, K.; Lu, J. Surface nanocrystallization (SNC) of metallic materials-presentation of the concept behind a new approach. J. Mater. Sci. Technol. 1999, 15, 193-197.

4. Tao, N.R.; Wang, Z.B.; Tong, W.P.; Sui, M.L.; Lu, J.; Lu, K. An investigation of surface nanocrystallization mechanism in Fe induced by surface mechanical attrition treatment. Acta Mater. 2002, 50, 4603-4616. [CrossRef]

5. Wu, X.; Tao, N.; Hong, Y.; Xu, B.; Lu, J.; Lu, K. Microstructure and evolution of mechanically induced ultrafine grain in surface layer of AL-alloy subjected to USSP. Acta Mater. 2002, 50, 2075-2084. [CrossRef]

6. Mordyuk, B.N.; Milman, Y.V.; Iefimov, M.O.; Prokopenko, G.I.; Silberschmidt, V.V.; Danylenko, M.I.; Kotko, A.V. Characterization of ultrasonically peened and laser-shock peened surface layers of AISI 321 stainless steel. Surf. Coat. Technol. 2008, 202, 4875-4883. [CrossRef]

7. Wang, T.; Wang, D.P.; Liu, G.; Gong, B.M.; Song, N.X. Investigations on the nanocrystallization of 40Cr using ultrasonic surface rolling processing. Appl. Surf. Sci. 2008, 255, 1824-1829.

8. Suh, C.M.; Song, G.H.; Suh, M.S.; Pyoun, Y.S. Fatigue and mechanical characteristics of nanostructured tool steel by ultrasonic cold forging technology. Mater. Sci. Eng. A 2007, 443, 101-106. [CrossRef]

9. Zhu, K.Y.; Vassel, A.; Brisset, F.; Lu, K.; Lu, J. Nanostructure formation mechanism of $\alpha$-titanium using SMAT. Acta Mater. 2004, 52, 4101-4110. [CrossRef]

10. Wang, K.; Tao, N.R.; Liu, G.; Lu, J.; Lu, K. Plastic strain-induced grain refinement at the nanometer scale in copper. Acta Mater. 2006, 54, 5281-5291. [CrossRef]

11. Zhang, H.W.; Hei, Z.K.; Liu, G.; Lu, J.; Lu, K. Formation of nanostructured surface layer on AISI 304 stainless steel by means of surface mechanical attrition treatment. Acta Mater. 2003, 51, 1871-1881. [CrossRef]

12. Wu, X.; Tao, N.; Hong, Y.; Liu, G.; Xu, B.; J, Lu.; Lu, K. Strain-induced grain refinement of cobalt during surface mechanical attrition treatment. Acta Mater. 2005, 53, 681-691. [CrossRef]

13. Sun, H.Q.; Shi, Y.N.; Zhang, M.X.; Lu, K. Plastic strain-induced grain refinement in the nanometer scale in a Mg alloy. Acta Mater. 2007, 55, 975-982. [CrossRef]

14. Zhang, Y.S.; Han, Z.; Lu, K. Fretting wear behavior of nanocrystalline surface layer of copper under dry condition. Wear 2008, 265, 396-401. [CrossRef]

15. Li, D.; Chen, H.N.; Xu, H. The effect of nanostructured surface layer on the fatigue behaviors of a carbon steel. Appl. Surf. Sci. 2009, 255, 3811-3816. [CrossRef]

16. Villegas, J.C.; Shaw, L.L.; Dai, K.; Yuan, W.; Tian, J.; Liaw, P.K.; Klarstrom, D.L. Enhanced fatigue resistance of a nickel-based hastelloy induced by a surface nanocrystallization and hardening process. Philos. Mag. Lett. 2005, 85, 427-438. [CrossRef]

17. Cao, X.J.; Murakami, R.; Pyoun, Y.S. Fatigue properties of a S45C steel subjected to ultrasonic nanocrystal surface modification. Appl. Surf. Sci. 2010, 256, 6297-6303. [CrossRef]

18. Niinomi, M. Fatigue characteristics of metallic biomaterials. Int. J. Fatigue 2007, 29, 992-1000. [CrossRef]

19. Fleck, C.; Eifler, D. Corrosion fatigue and corrosion fatigue behaviour of metal implant materials especially titanium alloys. Int. J. Fatigue 2010, 32, 929-935. [CrossRef]

20. Ferri, O.M.; Ebel, T.; Bormann, R. High cycle fatigue behaviour of Ti-6Al-4V fabricated by metal injection moulding technology. Mater. Sci. Eng. A 2009, 504, 107-113. [CrossRef] 
21. Link, F.; Munz, D. The initiation of stress corrosion cracking in Ti-6Al-4V alloy. Corros. Sci. 1973, 13, 809-811. [CrossRef]

22. Wang, G.C.; Liu, X.Y.; Zreiqat, H.; Ding, C.X. Enhanced effects of nano-scale topography on the bioactivity and osteoblast behaviors of micron rough $\mathrm{ZrO}_{2}$ coatings. Colloids Surface B 2011, 86, 267-274. [CrossRef] [PubMed]

23. Yang, W.E.; Hsu, M.L.; Lin, M.C.; Chen, Z.H.; Chen, L.K.; Huang, H.H. Nano/submicron-scale TiO 2 network on titanium surce for dental implant application. J. Alloy Compd. 2009, 479, 642-647. [CrossRef]

24. Benum, P.; Aamodt, A. Uncemented custom femoral components in hip arthroplasty. A prospective clinical study of 191 hips followed for at least 7 years. Acta Orthop. 2010, 81, 427-435. [CrossRef] [PubMed]

25. Daugaard, H.; Elmengaard, B.; Bechtold, J.E.; Jensen, T.; Soballe, K. The effect on bone growth enhancement of implant coatings with hydroxyapatite and collagen deposited electrochemically and by plasma spray. J. Biomed. Mater. Res. A 2010, 92, 913-921. [CrossRef] [PubMed]

26. Tong, W.P.; Tao, N.R.; Wang, Z.B.; Lu, J.; Lu, K. Nitriding iron at lower temperatures. Science 2003, 289, 686-688. [CrossRef] [PubMed]

27. Wu, B.; Wang, P.P.; Pyoun, Y.S.; Zhang, J.J.; Murakami, R.I. Study on the fatigue properties of plasma nitriding S45C with a pre-ultrasonic nanocrystal surface modification process. Surf. Coat. Technol. 2013, 216, 191-198. [CrossRef]

28. Wu, B.; Wang, P.P.; Pyoun, Y.S.; Zhang, J.J.; Murakami, R.I. Effect of ultrasonic nanocrystal surface modification on the fatigue behaviors of plasma-nitrided S45C steel. Surf. Coat. Technol. 2012, 213, 271-277. [CrossRef]

29. Stanzl-Tschegg, S. Fatigue crack growth and thresholds at ultrasonic frequencies. Int. J. Fatigue 2006, 28, 1456-1464. [CrossRef]

30. Morrissey, R.; Nicholas, T. Staircase testing of a titanium alloy in the gigacycle regime. Int. J. Fatigue 2006, 28, 1577-1582. [CrossRef]

31. Liu, X.L.; Sun, C.Q.; Hong, Y.S. Effects of stress ratio on high-cycle and very-high-cycle fatigue behavior of a Ti-6Al-4V alloy. Mater. Sci. Eng. A 2015, 622, 228-235. [CrossRef]

32. Cao, X.J.; Murakami, R.; Wang, Q.Y. Fatigue properties of Ti-6Al-4V subjected to $0.9 \%$ physiological saline solution. Int. J. Mod. Phys. B 2010, 24, 2518-2523. [CrossRef]

33. Liu, Y.J.; Cui, S.M.; He, C.; Li, J.K.; Wang, Q.Y. High cycle fatigue behavior of implant Ti-6Al-4V in air and simulated body fluid. Bio-med. Mater. Eng. 2014, 24, 263-269.

34. Jafari, S.; Raman, R.K.S.; Davies, C.H.J. Corrosion fatigue of a magnesium alloy in modified simulated body fluid. Eng. Fract. Mech. 2015, 137, 2-11. [CrossRef]

35. Gu, X.N.; Zhou, W.R.; Zheng, Y.F.; Cheng, Y.; Wei, S.C.; Zhong, S.P.; Xi, T.F.; Chen, L.J. Corrosion fatigue behaviors of two biomedical Mg alloy-AZ91D and WE43-In simulated body fluid. Acta Biomater. 2010, 6, 4605-4631. [CrossRef] [PubMed]

36. Wang, Y.M.; Liu, Y.; Liu, L. Fatigue behavior of a Ni-free ZrCuFeAlAg bulk metallic glass in simulated body fluid. J. Mater. Sci. Technol. 2014, 30, 622-626. [CrossRef]

37. Rubitschek, F.; Niendorf, T.; Karaman, I.; Maier, H.J. Fatigue behavior of a biocompatible ultrafine-grained niobium alloy in simulated body fluid. J. Mech. Behav. Biomed. 2012, 5, 181-192. [CrossRef] [PubMed]

38. Maruyama, N.; Mori, D.; Hiromoto, S.; Kanazawa, K.; Nakamura, M. Fatigue strength of 316L-type stainless steel in simulated body fluids. Corros. Sci. 2011, 53, 2222-2227. [CrossRef]

39. Wang, L.; Su, J.F.; Nie, X. Corrosion and tribological properties and impact fatigue behaviors of TiN- and DLC-coated stainless steels in a simulated body fluid environment. Surf. Coat. Technol. 2010, 205, 1599-1605. [CrossRef]

40. Bai, Y.; Li, S.J.; Prima, F.; Hao, Y.L.; Yang, R. Electrochemical corrosion behavior of Ti-24Nb-4Zr-8Sn alloy in a simulated physiological environment. Appl. Surf. Sci. 2012, 258, 4035-4040. [CrossRef]

41. Huang, R.; Han, Y. The effect of SMAT-induced grain refinement and dislocations on the corrosion behavior of Ti-25Nb-3Mo-3Zr-2Sn alloy. Mater. Sci. Eng. C 2013, 33, 2353-2359. [CrossRef] [PubMed]

42. Li, J.; Li, S.J.; Huang, H.H.; Bai, Y.; Hao, Y.Q.; Guo, Z.; Xue, J.Q.; Yang, R. Electrochemical and surface analyses of nanostructured Ti-24Nb-4Zr-8Sn alloys in simulated body solution. Acta Biomater. 2014, 10, 2866-2875. [CrossRef] [PubMed] 
43. Li, J.; Li, S.J.; Hao, Y.L.; Yang, R. Electrochemical characterization of nanostructured Ti-24Nb-4Zr-8Sn alloy in 3.5\% NaCl solution. Int. J. Hydrog. Energy 2014, 39, 17452-17459. [CrossRef]

44. Kokubo, T.; Takadama, H. How useful is SBF in predicting in vivo bone bioactivity. Biomaterials 2006, 27, 2907-2915. [CrossRef] [PubMed]

(). (1) (C) 2017 by the authors. Licensee MDPI, Basel, Switzerland. This article is an open access article distributed under the terms and conditions of the Creative Commons Attribution (CC BY) license (http:/ / creativecommons.org/licenses/by/4.0/). 